\title{
Assessing Students' Knowledge and Soft Skills Competency in the Industrial Training Programme: The Employers' Perspective
}

\author{
Lim Khong Chiu ${ }^{1}$, Nor Idayu Mahat ${ }^{2}$, Basri Rashid ${ }^{1}$, Norhanim A. Razak ${ }^{1} \&$ Hamimi Omar $^{1}$ \\ ${ }^{1}$ School of Tourism, Hospitality and Environmental Management, Universiti Utara Malaysia, Kedah, Malaysia \\ ${ }^{2}$ School of Quantitative Sciences, Universiti Utara Malaysia, Kedah, Malaysia \\ Correspondence: Lim Khong Chiu, School of Tourism, Hospitality and Environmental Management, Universiti \\ Utara Malaysia, Sintok, Kedah, Malaysia. E-mail: 1kc@uum.edu.my
}

Received: August 18, 2015

doi:10.5539/res.v8n1p123
Accepted: February 2, $2016 \quad$ Online Published: February 13, 2016

URL: http://dx.doi.org/10.5539/res.v8n1p123

\begin{abstract}
The importance of developing soft skills competency among students should be the priority of all the Higher Educational Institutions (HEIs) in order to ensure their graduates are marketable. Therefore, it is essential for HEIs to distinguish the knowledge and soft skill levels of their students so that strategies and intervention could be implemented to rectify their capabilities. The main purpose of this study is to evaluate the knowledge and soft skills competency from the employer's viewpoints on the Universiti Utara Malaysia (UUM) students participating in the industrial training programme. A total of 438 employers from different industrial backgrounds had participated in this study. A questionnaire consisting of five dimensions of soft skills which are basic knowledge, communication skills, practical skills, leadership, and attitude was utilized to collect data. The results of this study indicate that the employers were satisfied with the knowledge and soft skills competency portrayed by UUM students in preparing themselves for the real work environment. The employers from the service sectors were satisfied with students' performance in all dimensions of soft skills measured. However, employers from the factory and commerce sector perceived as moderate satisfaction for all dimensions of soft skills. Additionally, the employers of the factory and commerce sector assessed by giving the lowest satisfaction score for "hands-on" skills, but generally they satisfied with the students' communication skills. The information gathered can provide important insights from the perspective of organizations which is valuable in improving the overall hard and soft skills competency for future professionals and managers.
\end{abstract}

Keywords: industrial training, student's performance, employers, soft skills

\section{Introduction}

The importance of industrial training or internship program has been discussed by many researchers such as Lloyd and Briston (2006), Barney and Pleban (2006), Griffith and Wilson (2003) and Beck and Kosnick (2002). Most of these studies critically discussed the change of attitude that should be possessed by students when they complete the training. Students may possess good attitudes, better skills and maturity, but their mood (anxiety, job satisfaction, perception and efficiency) may change unconsciously throughout the period (Teng, 2008). These findings demand further research to be done especially in developing a theoretical framework of industrial training in relation to smart partnership. A deliberate plan of industrial training programs will prepare students for quality young employees that could bring benefits to the country economically.

The period of formal industrial placement or practical training has long been implemented in the university educational programs. The benefits of exposing students with "real life" experience have not been denied by both academicians and industry practitioners. They have acknowledged that the "hands-on" experience gathered from training can bridge the gap between theory and practice (Barrow \& Walsh, 2002). This experience enables them to practice the theory learned in the classroom and to apply the relevant skills and competencies during the practical training period without conforming to traditional classroom setting. Furthermore, students' involvement in practical training can set directions and promote positive outcomes, as well as provide career opportunities (Lim, 2006).

Previous studies have focused on students' perception of their experiences and lessons learned (Mihail, 2006; Warinda, 2013). Mihail (2006) found out that the structural weakness of internship programmed are related to the 
limited length of time, low student pay, and long working hours. Internship programs differ from course to course. On the other hand, unstructured internship programs which force the students to do the same repetitive job on a daily basis when they expect challenging work where they could have opportunities to learn and to contribute to the organization (Rothman, 2007). An intern may not be able assigned to advance projects, but repeated assignments could give negative impressions on their experiences (Crumbley \& Summers, 1998).

Thus, it is essential for universities to investigate how their students are accepted in the job market. As reported by Fairuzza, Nazuir, and Wahid. (2011), a significant percentage of the graduates of the local Malaysian universities are still lacking relevant soft skills competency, leading to their unemployment in a highly competitive job market. The National Economic Action Council (2003) indicated that there is a mismatch of competency between the industry requirements and the graduates produced by the universities. Likewise, the findings by the Universiti Tun Hussein Onn Malaysia showed that there are gaps between the importance of soft skills needed in the workplace and the graduates' soft skills competency performance as perceived by the Human Resource Practitioners (Fairuzza, Nazuir, \& Wahid, 2011). Furthermore, stressing on the importance of developing soft skills, the Education Ministry of Malaysia has planned under the blueprint to implement a two-year learning and two-year practical training for university courses. According to the Minister of Higher Education, Datuk Seri Idris Jusoh, it would make Malaysian graduates more marketable through English proficiency and communication skills, among others (The Star, June 19, 2015). Meanwhile, the strategy is aligned with the Malaysia Education Blueprint 2015-2025 (Higher Education) objectives to develop talent and innovation towards producing holistic, entrepreneurial and balance graduates (The Star, August 16, 2015). In that regards, realizing the importance to understand the quality of undergraduates, this paper will highlight a study that investigates the performance of Universiti Utara Malaysia (UUM) students in the industrial training programs. The main focus of the study is to measure the students' level of soft skills and basic knowledge which are commonly sought by employers. The findings of the investigation will be helpful for the university to identify loopholes in the offered programs, hence some necessary actions can be planned to overcome the problems.

\section{Literature Review}

\subsection{The Roles of Internship Programme}

According to the University of Wisconsin-Stout (2008), internships are conducted under the directions (direct or indirect) of an instructor and are designed to provide "real life" or "on-the-job" experiences for the student, with the opportunity to critique and refine skills through contact with the instructor, and with an on-site supervisor assigned to work with the intern at the work site. For decades, the implementation of experiential education as a legitimate pedagogy have expanded the teaching and learning environment outside-the-classroom. Employers have well recognized the contribution from academic driven internships as they believe via this medium, it would present them with supplementary human resources in this growing economy. Internships have become ubiquitous among smaller participating companies as a credible mean to obtain over-achieving and talented employees that can be absorbed to their work force (Mihail et al., 2006).

Past researches showed that firms use internship as a medium to recruit future employee (Gault, 2000; Callanan \& Benzing, 2004; Hurst \& Good, 2010). Gault, Leach and Duey (2010) posit that organizations which hire former interns save between USD 6200 to USD 15000 per person in recruitment and training cost. A study conducted by McDonald, Birch, Hitchman, Fox, and Lido (2010) and Beard (1998) showed that companies are more likely to hire based on work experiences. However, there seem to be a blunder between expectations of companies and students. Students expect to be given the training during their placement, whereas companies expect students to be well equipped with the knowledge and hands-on skills acquired in the university before starting their internship (Gault et al., 2010). Being a critical component of higher education, internship is believed to create a win-win situation for the students, organization and the university (Coco, 2000). The empirical study by Gault et al. (2000) on career success revealed that interns showed to be receiving job offers 10 weeks sooner and salary which were ten per cent higher compared to their non-counterpart.

On the matter of up scaling the current internship programs, Beard (2007) postulates that comprehensive programed assessment tools that are used in evaluating the internship experience, student's learning, and satisfaction with the internship programs can provide pivotal insights from the perspective of student intern and the external internship supervisor. As for today, countless internship assessment methods by the supervisor were based on the Kolb's view of learning in which the model consists of the four components: Concrete Experience (CE), Reflective Observation (RO), Abstract Conceptualization (AC) and Active Experimentation (AE) to support the use of experiential learning (Kolb, 1984; Sweitzer \& King, 2009). 


\subsection{Hard Skills versus Soft Skills}

Both hard skills and soft skills are inarguably imperative to succeed in a particular professional job. By definition, hard skills are learnable technical skills needed to perform a certain task. It is the ability to use more of the left-logical side of the brain to do something and includes being a subject matter expertise in certain professional skills such as math, programming, and engineering (Hard Skills vs. Soft Skills, 2013) Thus, it is undeniable that hard skills can be developed through training and practice in that certain field. For example, a mathematician counting the mass of a certain item using a particular formula is a display of hard skills.

In contrast, soft skills includes more of the use of the right side of the brain and can also be defined as a skills of employability. These skills are not taught well in school. Thus, it can be self-taught and developed through trial and error. Soft skills incorporates the skill of effective communication, problem-solving, creative thinking and also leadership. For example, jobs in the field of sales and marketing, or management positions are examples of jobs that require more soft skills rather than hard skills. For instance, we all have worked with or work for senior positions that is younger than us and doesn't seem as knowledgeable. So, it can be concluded that their soft skills is the key that skyrocketed their position. Another good example would be a car dealer. We just need sufficient information on the car we are selling. But instead, our persuasion and good communicative skills are more important to get the car sold.

It is an undeniable fact that both hard and soft skills are equally important criteria especially in employability. For instance, a manager of a company will definitely compare your hard skills with the job that you are targeting and decide whether you are qualified for the particular job (Han, 2011). However, fulfilling only the hard skills criteria may not be the only aspect to be concerned about as soft skills are vital too. For example, we might have to go through interviews where we need to display an array of soft skills such as effective communication, persuasion and also leadership skill to be able to impress the interviewer to hire us. Thus, to ensure the quality standard of the programs offered by the Higher Education Providers (HEPs) in the Malaysian Higher Institutions, the importance of both hard and soft skills has been emphasized by the Ministry of Higher Education via Malaysia Qualification Agency (MQA) which introduced the eight Malaysian Qualification Framework (MQF) learning outcome domains that required to achieve in the learning outcomes of all programs (MQA, 2010). The programmes learning outcome domains suggested are as follows:
i. Knowledge
ii. Practical skills
iii. Social skills and responsibilities
iv. Ethics, professionalism and humanities
v. Communication, leadership and team skills
vi. Scientific methods, critical thinking and problem solving skills
vii. Lifelong learning and information management
viii. Entrepreneurship and managerial skills

\subsection{Student Performance in Job Market}

\subsubsection{Student Quality}

Quality of students in the job market can be investigated generally in two possible ways, either when (i) students have graduated from university and tied into the job market or (ii) students have not yet left the university but they are in a workplace for industrial training purposes as part of their study. The former may give a better insight about students' motivations, attitudes towards their jobs and skills. However, tracking them in job markets is difficult and consumes a high amount of cost. As a matter of fact, there is a possibility that the number of participating organizations in a study may be too small.

In comparison to the former, the latter offers better participation from organizations, but it may be slightly biased to reflect the performance and capability of students as employees. For example, students are easily uninspired and lack of interest in their activities if they are treated as aliens and seldom given trustworthy tasks like permanent employees. Therefore, they may not be able to show their true quality on the job as suggested by Teng (2008).

The industrial training programs in Universiti Utara Malaysia (UUM) require students to undergo their training in their final semester after all courses have been completed. These programs prepare students with soft skills needed by industry and they will gain new knowledge through their positive participation in the workplace 
within four to six months of industrial training. The main reason for offering the industrial training programs during the final semester is to allow the trainees to acquire employment offers before the training ends, thus reducing the unemployment problem among the graduates (Praktikum, 2005).

Since, industrial training has been made a prerequisite for most undergraduate programs in UUM, students' performance must be evaluated to ensure the programs are indeed effective in enhancing students' thinking skills, communication skills, attitude, appearance and other necessary skills that should be possessed by a good employee. In other words, it is referring to students' soft skills that help people work and socialize well with others. In short, they are the good manners and personality traits needed to get along with others and build positive relationships. In the workplace, soft skills are considered a complement to hard skills, which refer to a person's knowledge and occupational skills (www.investopedia.com/terms/s/soft-skills.asp).

Currently, in most of the HEIs, all activities performed by students during the training period will be evaluated and graded by the industry supervisors and the assigned university lecturers. Subsequently, a survey was carried out as an alternative to acquiring feedbacks from organizations regarding students' performance which include soft skills.

\subsubsection{Skills Acquisition}

Students should portray their knowledge and skills that will enable them to cope more readily with the demands of the workplace today. Eventually, through their "real life" working experience is an opportunity for them to develop their personal and employability skills. The employability skills consist of technical skills and generic skills, which are vital in working place. Technical skills are skills that are related to certain topics and usually we gain from a formal classroom teaching. For example, the knowledge and abilities are needed to accomplish mathematical, engineering, scientific or computer-related duties, as well as other specific tasks. Meanwhile, generic skills are non-technical skills that are highly associated with employability. Generic skills can be applied across a variety of subject domains, jobs and life contexts which associated with soft skills where our graduates are still lacking and need a lot of improvement to meet employers' expectations (Fairuzza, Nazuir, \& Wahid, 2011). In addition, according to their study, all skills identified in the soft skills such as communication skill, creative and critical thinking, teamwork, programmed and project management skill, and decision making and problem solving skill in the soft skills training of the Intel Elite Programmed are important in working place. This study concludes that lacking of those soft skills becomes the most likely factors to the unemployment issue of the graduates.

Moreover, a study of the participation of organizations in the industrial training programs by Bailey, Hughes and Barr (2000) reveal that skills possessed by interns are at least as good as the entry-level workers. These similarities occur when the investigation was carried out on several skill categories including attendance, reliability, attitude, productivity, training required to learn the job, communication skills, writing skills, mathematics skills and technical skills. Therefore, it is crucial for the HEIs to assess on their students' knowledge and soft skills performed in the industrial training programs. Generally, students are supposed to get exposure to real work environment and be able to harness their skills and competencies upon completion of the training (Peacock \& Ladkin, 2002). These added values can be used as a milestone to understand whether the objectives of the industrial training programs are successfully achieved. The issue is what are the expected skills and competencies that should be attained by the students from the programs?

In relation to the skills examined, Mihail (2006) used 22 areas of skills from Murray and Robinson (2001) to investigate the most important benefits attained by students from the industrial training at Greek universities. These areas of skills were extracted from the three main categories of skills which are academic, enterprise and personal development skills. The first category assembles skills that are related to learning such as written and spoken communication, computer literacy and specialist knowledge. The second category focuses on the ability to work in groups, to prioritize tasks and to manage time and finally, the last category consists of quality of oneself such as self-confidence, creativity and ability to solve problems. His study discovered that students had the chance to enhance specialist knowledge and becoming much better with information technology. Besides, the industrial training shapes the students to be manageable in time management and prioritizing work, as well as giving them opportunities to have open dialogue and experience working as a team. Hence, the analysis of the related literature reveals that there are at least five interrelated skills, namely, basic knowledge, communication skills, practical skills, leadership and attitude that can measure students' performance at workplaces. Thus, in this study, those identified skills were included for the assessment of the UUM students' knowledge and soft skills performed in the industrial training programmed. 


\section{Method}

\subsection{Population of the Study}

This study obtained feedbacks from organizations on performance of UUM students from their experience with the industrial training programs. A group of students from various academic programs who went for industrial training in December 2006/2007 (later known as A062) was chosen as a population and the distribution of students' academic programs is tabulated in Table 1 .

Table 1. Number of students involved in the industrial training program December 2006/2007 session based on academic area of study

\begin{tabular}{lc}
\hline Academic Programs & Number of students \\
\hline Accounting & 43 \\
Banking, Finance and Insurance & 351 \\
Business Management & 588 \\
Communication & 189 \\
Economy and Decision Sciences & 110 \\
Human Resource & 82 \\
Information Technology and Multimedia & 348 \\
International Affairs & 177 \\
Public and Development Management & 340 \\
Social Work & 80 \\
Management of Technology & 235 \\
Tourism and Hospitality & 122 \\
\hline
\end{tabular}

\subsection{Respondent Identification}

There were 712 organizations involved in placing UUM students for industrial training programs for A062 session. They accepted a student or more at one time, and the training may take two and the half months, four months or six months depending on the programs of study. Some of these organizations have been participating in the industrial training programs for many years and others may be first timers. However, such status will not be a major barrier in their assessment of students' performance. All organizations participating in the industrial training programs must provide their backgrounds for record purposes and this information is stored in the Practicum System (SISPR), and is used in this study.

\subsection{Questionnaire Development}

The questionnaire development process is divided into four phases as the following: (i) analysis of the related literature, (ii) focus group, (iii) item development, and (iv) face or content validation. List of skills as highlighted by Mihail (2006), Bailey et al. (2000) and Breaugh (2008) is used as a basis to identify skills that should be attained by the students from this study. Later, these skills are grouped into four dimensions of the soft skills and one dimension regarding the basic knowledge through discussion by experts from the University Industrial Training Programs in a focus group session. Results obtained by this group lead to the designing of the questionnaire and finally, the questionnaire is tested through face and content validation process before it is finalized.

\subsubsection{Identifying Knowledge and Soft Skills}

The questionnaire focuses on four dimensions of soft skills which are (i) communication skills, (ii) practical skills, (iii) leadership (iv) attitude, and one dimension pertaining to basic knowledge. Measurable components were then identified for each dimension and listed in Table 2. 
Table 2. Dimension of knowledge and soft skills' measurable components

\begin{tabular}{ll}
\hline Dimension & Measured Component \\
\hline Basic knowledge & $\begin{array}{l}\text { Knowledge on the field of study, responsibility, attached industry and current } \\
\text { issues. }\end{array}$ \\
Communication skills & $\begin{array}{l}\text { Level of capabilities to deliver thought, opinion, and perform negotiation with } \\
\text { customers, peers and officers in Bahasa Melayu (Malay language) and English } \\
\text { language using both writing and speaking. }\end{array}$ \\
Practical skills & $\begin{array}{l}\text { Components in this dimension include students' ability to use computers and } \\
\text { technology and solve the assigned problems. }\end{array}$ \\
Leadership & $\begin{array}{l}\text { This dimension consists of components such as the ability to make decisions } \\
\text { pertaining to the task planning, to lead other colleagues, willingness to accept } \\
\text { responsibilities. }\end{array}$ \\
Attitude & $\begin{array}{l}\text { Components in this dimension include level of commitment on the job, time } \\
\text { management, willingness in giving assistance when needed and tasks } \\
\text { prioritization. }\end{array}$ \\
\hline
\end{tabular}

Basic knowledge aims at measuring students' awareness about getting information about the attached organization, the given tasks or projects, the application of subject learning and some current issues surrounding them. The communication skills, evaluate students' capability to communicate in writing and speaking when they deliver their tasks. These skills are tested in Bahasa Melayu, the mother tongue for most Malaysians, and English, the language that is commonly used in private and corporate sectors in Malaysia.

One of the main objectives of industrial training programs is to provide students a platform for gaining either knowledge or theories in a real work setting. Therefore, this study investigates how students are able to integrate knowledge exposed to them in the classroom in solving real problems using ICT, technologies and other possible solution solutions. The components under practical skills will determine the level of capability to handle technologies commonly used in management situations. The measurements used in this dimension are not included as ones that are often used in medicine and engineer industrial training programs that demand students to use special technologies or systems.

Leadership aims at measuring the quality in decision making among students. Components listed in this dimension investigate the students' ability in planning and taking appropriate action for a given task, leading and working in a team and responsibility towards a given task. Finally, the attitude dimension investigates students' manner and discipline during the training. This dimension attempts to identify students' willingness to improve themselves, commitment to their jobs, confidence in taking a challenge, discipline in time management and willingness in helping peers to achieve the same objectives.

\subsection{Questionnaire Design}

The questionnaire consists of five parts which are; (I) profile of the participating industry, (II) measurement of the five soft skills of students' performance, (III) measurement of the performance of the University in managing the industrial training programs, (IV) industry opinion towards the industrial training programs and (V) employers' suggestion for enhancing the industrial training programs as they prefer to. The focus of this paper will be on parts I, II and V respectively. All the identified components as listed in Table 2 are measured using the Likert scale ranges from 1 to 5 in part II of the questionnaire. The lowest value indicates less satisfactory performance and the level of satisfactory increases as the value approaching 5.

\subsection{Data Collection}

The questionnaire was distributed through mail to the officer in each organization who was responsible to supervise the attached trainees. Due to poor respond at the beginning of the data collection process, the questionnaire was again distributed to organizations by visiting them. Besides, phone calls were also made to remind the respective officers to respond. Subsequently, this effort resulted into 438 organizations (61.5\%) participating in the survey.

The completed questionnaires were analyzed using descriptive statistical analysis to explain about the background of the sample and their response. A content analysis was also performed to determine some potential suggestions to be considered for further improvement of this program. 


\section{Results and Discussion}

Organizations involved in this study were grouped into four sectors: private organization (45.1\%), government $(42.3 \%)$, local government companies $(8.0 \%)$ and non-local government companies (4.6\%). From this list, 54.7\% of the organizations have been participating with the UUM industrial training programs for more than a year.

Analyses conducted on the returned questionnaires discover that students were good in hands-on skills, leaderships and disciplines (see Table 3). However, students seem to face some difficulties in understanding the new environment surrounding them as well as communicating in English language confidently. This may be due to a crammed time schedule during academic semesters that cause to isolate themselves from the community, especially when it is related to global issues that are beyond their subject of studies. Therefore, they need some ample times to understand new issues and respond to the issues. Meanwhile, the moderate performance in English language as a medium of communication could be possibly due to less exposure on practicing English language in their social life.

In addition, the spider-web chart as presented in Figure 1 summarizes organizations' perceptions on the investigated dimension of students' knowledge and soft skills performances. This chart identifies the critical signal of the weaknesses on the performance based on type of organizations. A short brief about the spider-web chart is as follows: a perfect performance will score 5 points, hence if all the five skills are excellent, then each skill scores 5 points. Labelling the points in the spider-web chart and joining the points lead to a perfect pentagon. The results in Figure 1 indicate the differences of skills sought by types of organizations. Interestingly, among these types of organizations, the factory and commerce rated the lowest satisfaction score for hands-on skills, but they satisfied with the students' communication skills. These findings can be implied that the nature of the jobs in the factory and commerce may not be too involved with the public in most of their activities hence less communication would occur. However, students are demand to have a good basic knowledge on some technical aspects and hands-on skill especially when it is related to the tasks and responsibilities in relation to the respective jobs to be accomplished.

Table 3. Table of performance for five measured soft skills (in percentage)

\begin{tabular}{lllll}
\hline \multirow{2}{*}{ Skills } & \multicolumn{4}{c}{ Level of performance } \\
& Unsatisfactory & Moderate & Satisfactory & Excellent \\
\hline i. Basic knowledge of ... & & & & \\
program of study & 0.7 & 28.4 & 49.7 & 21.2 \\
jobs or responsibilities & 1.1 & 31.7 & 45.3 & 21.8 \\
organization & 3.9 & 44.6 & 35.4 & 16.1 \\
general and current issues & 3.2 & 39.1 & 42.5 & 15.2 \\
ii. Communication in ... & & & & \\
writing: native language & 0.5 & 16.6 & 47.0 & 35.9 \\
writing: English & 6.9 & 44.0 & 38.7 & 10.4 \\
oral: native language & 0.0 & 14.5 & 45.4 & 40.1 \\
oral: English & 6.0 & 46.0 & 37.6 & 10.4 \\
iii. Hands-on skills and competency in & & & \\
computer and software literacy & 0.2 & 14.4 & 47.7 & 37.6 \\
doing job & 1.1 & 19.9 & 45.3 & 33.3 \\
solving the given problem & 2.8 & 31.0 & 45.9 & 20.4 \\
iv. Leadership for ... & & & & \\
\hline
\end{tabular}




\begin{tabular}{lllll}
\hline decision making & 2.8 & 41.6 & 43.0 & 12.7 \\
leading peers & 3.5 & 45.7 & 36.6 & 14.2 \\
teamwork & 0.5 & 16.3 & 46.9 & 36.3 \\
integrity & 0.2 & 13.6 & 45.5 & 40.7 \\
responsibility & 0.2 & 13.8 & 42.1 & 43.9 \\
quality job & 0.9 & 27.4 & 46.8 & 24.9 \\
v. Attitude and Discipline in $\ldots$ & & & & \\
focus during the training & 0.8 & 2.2 & 42.9 & 34.1 \\
time management & 0.8 & 15.1 & 40.5 & 43.7 \\
lending help & 0.0 & 19.0 & 40.5 & 40.5 \\
\hline
\end{tabular}

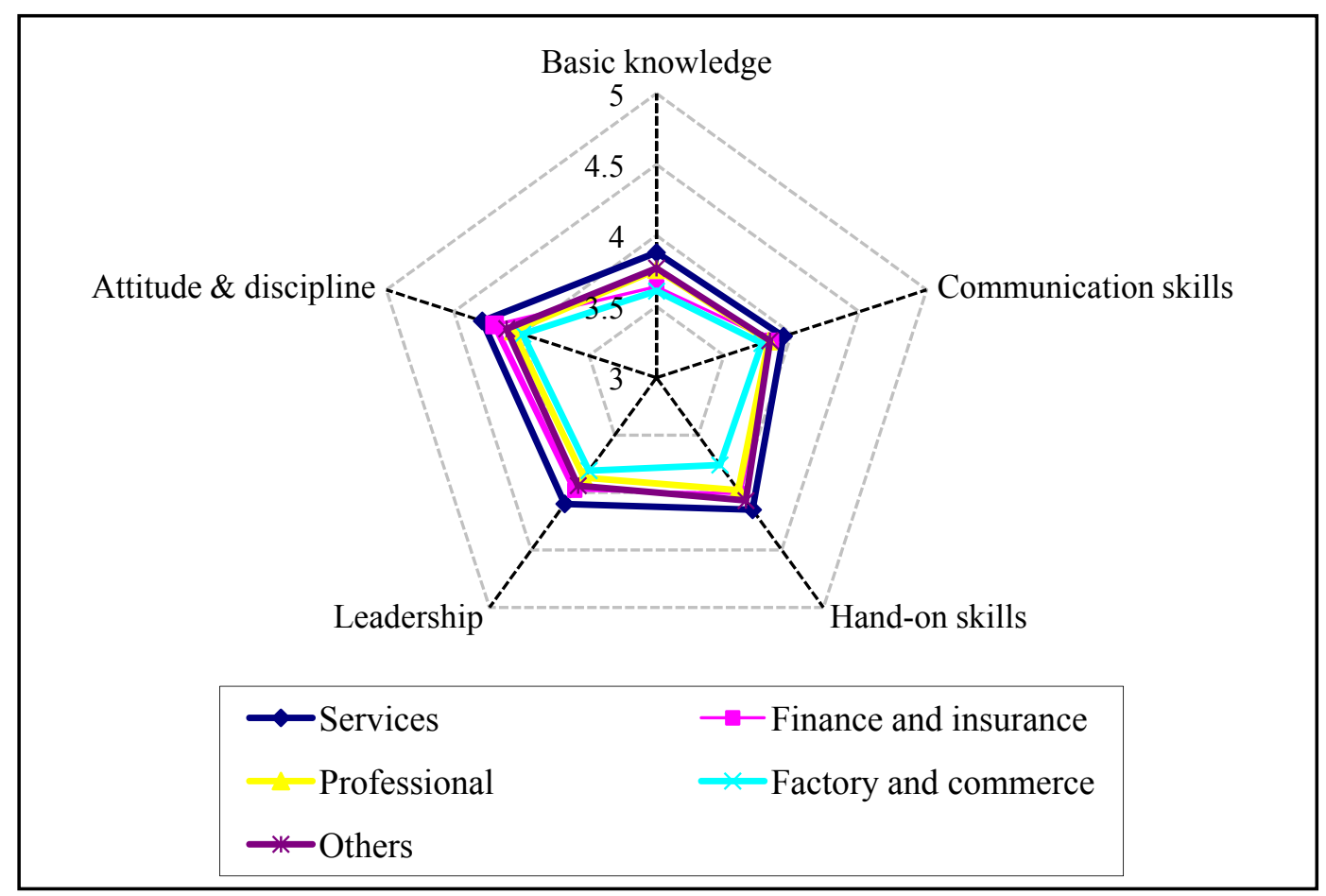

Figure 1. Summary of students' performance based on five soft skills

In comparison to Table 3, Figure 1 shows the variation of organizations' perception on the skills measured. Organizations from the services area satisfy with students' performance in all skills and the scores are similar. These perceptions are shared with other organizations except for factory and commerce as they rated moderate satisfaction for all skills. However, the results obtained in this study should not be interpreted that students with management background of studies do not fit into such industries. There are some departments in the factory that they are possibly can be accepted such as financial department and human resource department. Students may need some time to get familiarize with the technical aspects of which are the major concern of these industries.

This study also discovers that there is no difference in job performances between UUM students and other students from local universities. There are about $78.0 \%$ participating organizations in this study placed students from other local universities for industrial training purposes. Therefore, it is a need to identify some differences in the level of skills among the students. In general, UUM students are rated as good in soft skills by the 
participating organizations. Such performance is also rated to the other local graduates. This result can be understood that local students are having similar performance despite on the differences of teaching and learning approaches by the universities. Thus, it can be concluded that the issue of lack of basic knowledge and incompetence in communication occurs among the local students. A more strategic plan that includes a smart collaboration between universities and industry must be carried out to minimize such weaknesses. In addition, the participating organizations also suggest some skills that can be embedded into a management student. These skills are basic accounting and financial skills, critical thinking and organization management. Such skills are considered appropriate because all employees, regardless of their positions in an organization, must understand how the organization is managed. These skills are not only applicable to the services orientation organizations, but are also suitable to various organizations' backgrounds.

In summary, UUM students' performances are satisfactorily in their overall practical skills, leadership qualities, and discipline although they do not have work experience. Most types of organizations indicate similar perception of UUM's students except for the factory and commerce organizations. However, students' basic knowledge and confidence to converse in the English language must be strengthened. Most students are rated well for knowledge pertaining to their program of study, but they are not equipped themselves with new information beyond their pursued study area. Meanwhile, the issue of lack of confidence to communicate in English language still remains, and it needs some structured activities or programs to overcome the problem.

\section{Conclusions}

The feedbacks of this study regarding students' knowledge and soft skills performance that obtained from the industrial training programs can provide important insights for the university and the organizations which can be shared with the programmers' coordinators and administrators. The employer's viewpoints should be considered important components of a comprehensive evaluation of students' performance. Thus, the resulting feedbacks can be valuable in improving the industrial training or internship programs as well as the overall academic programs for future professionals and managers.

Five categories of student performance are focused in this study namely, basic knowledge, communication skills, hands-on skills, leadership skills, and attitude and discipline. Each category consists of selected soft skills and knowledge that best reflect students from management backgrounds. However, one should consider some added value skills when dealing with technical internship programs such as medicine, engineering and pure science.

Furthermore, the future study could be planned in order to identify some potential differences of soft skills among local and abroad graduates, especially those who are from the field of the management studies. Factors that contribute to such differences much be identified and the results will be useful for local higher institutions to generate better curriculum in their endeavor to produce better knowledgeable and skillful human capital.

\section{Acknowledgements}

The authors would like to extend their appreciation to the Universiti Utara Malaysia and Research Innovation Management Centre for the financial support and who make this presentation possible.

\section{References}

Ann-Marie Khor. (2015, August 19). Towards an integrated grading system. The Star, 8-9.

Bailey, T., Hughes, K., \& Barr, T. (2000). Achieving scale and quality in school-to-work internships: Findings from two employer surveys. Educational Evaluation and Policy Analysis, 22(1), 41-64.

Barney, D., \& Pleban, F. (2006). Pre-service physical education teacher's perception of teaching before and after a semester long elementary physical education practicum experience. Physical Educator, 63(1), 46-52.

Barrows, C., \& Walsh, J. (2002). Bridging the gap between hospitality management programs and the private club industry. International Journal of Contemporary Hospitality Management, 14(3), 120-127. http://dx.doi.org/10.1108/09596110210424411

Beard, D. F. (2007). Assessment of internship experiences and accounting core competencies. Accounting Education, 16(2), 207-220. http://dx.doi.org/10.1080/09639280701234625

Beck, C., \& Kosnick, C. (2002). Components of a good practicum placement: Student teacher perceptions. Teacher Education Quarterly, 29(2), 81-97.

Callanan, G., \& Benzing, C. (2004). Assessing the role of internships in the career-oriented employment of

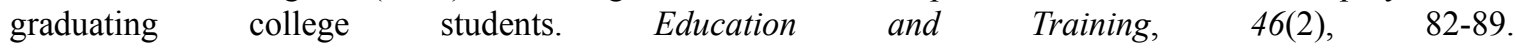
http://dx.doi.org/10.1108/00400910410525261 
Coco, M. (2000). Internships: A try before you buy arrangement. Advanced Management Journal, 65, 41-47.

Crumbley, D., \& Sumners, G. E. (1998, October). How businesses profit from internships. Internal Auditor, 55, 54-59.

Fairuzza, A. B. H., Mohamad Nazuir, B. B. A. T., \& Wahid, C. B. R. (2011). Employers'perception on soft skills of graduate: A study of Intel Elite soft skills training. Paper presented at the International Conference on Teaching \& Learning in Higher Education (ICTLHE 2011), Hotel Equatorial Melaka, on 21-23 November 2011.

Gault, J., Leach, E., \& Duey, M. (2010). Effects of business internships on job marketability: The employers' perspective. Education \& Training, 52(1), 76-88. http://dx.doi.org/10.1108/00400911011017690

Gault, J., Redington, J., \& Schlager, T. (2000). Undergraduate business internships and career success: Are they related? Journal of Marketing Education, 22, 45-53. http://dx.doi.org/10.1177/0273475300221006

Griffith, C. H., \& Wilson, J. F. (2003). The loss of idealism throughout internship. Evaluation \& the Health Professions, 26 (4), 415-426.

Han, L. (2011) Hard Skills vs. Soft Skills-Difference and Importance. Retrieved from https://bemycareercoach.com/soft-skills/hard-skills-soft-skills.html

Hard Skills vs. Soft Skills. (2013, March). Retrieved from http://www.professionsnorth.ca/career-tools/tips/2013-Mar

Hurst, J. L., \& Good, L. K. (2010). A 20-year evolution of internships: Implications for retail interns, employers and educators. The International Review of Retail, Distribution and Consumer Research, 20(1), 175-186. http://dx.doi.org/10.1080/09593960903498342

Kolb, D. A. (1984). Experiential Learning: Experience as the source of learning and development. Englewood Cliffs, N.J.: Prentice-Hall. http://dx.doi.org/10.1002/job.4030080408

Lim, K. C. (2006). Coordinator's reflection. Buletin Praktikum Pusat Praktikum, 1, 5-6.

Lloyd, S., \& Briston, S. (2006). Modeling mentorship and collaboration for BSN and MSN students in a community clinical practicum. Journal of Nursing Education, 45(4), 129-131.

McDonald, J., Birch, C., Hitchman, A., Fox, P., \& Lido, C. (2010). Developing graduate employability through internships: New evidence from a UK university. In S. Halley, C. Birch, D. T. Tempelaar, M. McCuddy, N. H. Nanclares, S. Reeb-Gruber, ... E. Nelissen (Eds.), Proceedings of the 17th EDINEB Conference: Crossing borders in education and work-based learning (pp. 349-358). London: FEBA ERD Press.

Malaysia Qualification Agency (MQA). (2010). Code of practice for Programme Accreditation. Petaling Jaya: MQA.

Mihail, M. (2006). Internships at Greek Universities: An exploratory study. Journal of Workplace Learning, 18 , 28-41. http://dx.doi.org/10.1108/13665620610641292

Murray, S., \& Robinson, H. (2001). Graduates into sales-Employer, student and university perspectives. Education Training, 43(3), 139-145. http://dx.doi.org/10.1108/EUM0000000005459

National Economic Action Council. (2003). Preliminary findings: Study on the employability of Malaysian graduates. A presentation to Executive Director of NEAC on $9^{\text {th }}$ April 2003 (not published).

Peacock, N., \& Ladkin, A. (2002). Exploring relationships between higher education and industry: A case study of a university and the local tourism industry. Industry and Higher Education, 16, 393-401. http://dx.doi.org/10.5367/000000002101296568

Praktikum, P. (2005). Buku panduan praktikum. Sintok: Universiti Utara Malaysia.

Rothman, M. (2007). Lessons learned: Advice to employers from interns. Journal of Education for Business, 140-144. http://dx.doi.org/10.3200/joeb.82.3.140-144

Sweitzer, H. F., \& King, M. A. (2009). The successful internship: Personal, professional, and civic development. (3rd ed.). Belmont CA: Brooks/Cole.

Teng, C. (2008). The effects of personality traits and attitudes on student uptake in hospitality employment. International Journal of Hospitality Management, 27, 76-86.

University of Wisconsin-Stout. (2008). Glossary of academic terms. In Deuster, J. T. (2009), A perspective on manager on student internship experiences. Unpublished Master of Science degree dissertation- University 
of Wisconsin-Stout.

Warinda, T. (2013). Accounting students' evaluation of internship experiences from a skills perspective. International Journal of Asian Social Science, 3(3), 783-799.

22,500 being trained to teach English better. (2015, June 19). The Star, p. 14.

\section{Copyrights}

Copyright for this article is retained by the author(s), with first publication rights granted to the journal.

This is an open-access article distributed under the terms and conditions of the Creative Commons Attribution license (http://creativecommons.org/licenses/by/3.0/). 